\title{
The integration of a high-speed train station in Valencia City
}

\author{
J. L. Miralles i Garcia \\ Department of Urban Planning, \\ Polytechnic University of Valencia, Spain
}

\begin{abstract}
Spain is a country with a large high-speed rail network (HSR or AVE by its initials in Spanish). Most of this railway network was built between 2000 and 2007. Network deployment involves addressing many issues, particularly station localization. The traditional railway network in Spain has a different track gauge to that in the rest of Europe so historical stations do not always serve the highspeed network. In 2000, the first proposal for the railway network of Valencia was published. Our research team realized two studies on the metropolitan railway network and better station localization in 2002 and 2006. In particular, these studies proposed an intermodal station in an airport to integrate travel flights and travel high-speed train. Between 2008 and 2010, a new provisional high-speed railway station in Valencia was built: Joaquín Sorolla Station. This paper analyses the initial proposal, the actual situation and trends after 2006 on airport-railway station relations in other cities, such as Madrid or Barcelona.
\end{abstract}

Keywords: city-train integration, multimodal transport integration.

\section{Introduction}

In 1987, the government approved a rail transport plan to modernize the rail network in Spain. The objective was to improve conventional trains and rail net for $200-250 \mathrm{~km} / \mathrm{h}$ speed as a maximal speed. A few years afterwards, the government decided to put off the plan and execute the first high-speed line (AVE services in Spanish) between Madrid and Seville, which opened in the Universal Exposition of Seville in 1992. This service has speeds of about $300-350 \mathrm{~km} / \mathrm{h}$. Investment in this infrastructure consumed all the planned budget for the rail plan. The high-speed train station in Madrid was located in the centre of the city, in Atocha. 


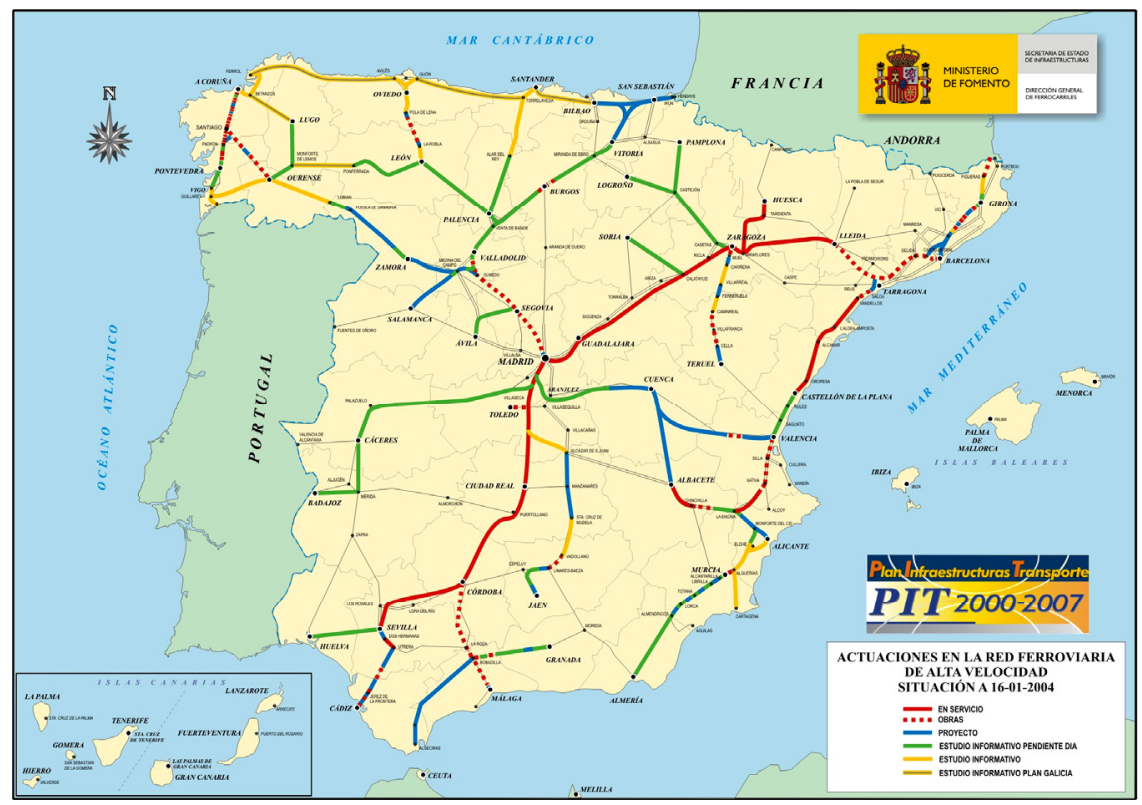

Figure 1: $\quad$ PIT 2000-2007, degree of development rail network in 2004. (Source: Ministerio de Fomento, Spain.)

In 1999, a new plan was approved: Infrastructures Plan 2000-2007. In Spain, the rail network has a special width of 1,668 meters; different from the European width of 1,435 meters (width international or UIC). Integration of the entire European rail network involves changing the Spanish rail network to the European width. This change is an expensive process that can take a long time.

The first high-speed train was built in the European width. From that moment, we have had two rail networks in Spain; one Iberian and another with a European or UIC gauge. It is planned that, gradually, the train network medium or long distance will reconvert to the European gauge.

In 2005, the government changed the infrastructural plan to the new Infrastructure and Transport Strategic Plan (Plan Estratégico de Infraestructuras $y$ Transporte 2020 or PEIT 2020) [1]. The new plan provided for an extensive high-speed rail network in Spain. After the Madrid-Seville line, the most important line will be Madrid-Barcelona. Also, Madrid-Valencia and BarcelonaValencia (not executed to date). This ambitious plan was approved during the period of the housing bubble (1997-2007) with extraordinary growth expectations. The corridor which has the most travellers is Madrid-Barcelona, a connection of two important cities in Spain. The second corridors most important are MadridValencia and Barcelona-Valencia.

At this time, the official position on the high-speed train station was in favour of locating it in the centre of the city; the place of maximum accessibility for all people. Thus, the new high-speed station for Barcelona is planned to be in Sans city centre. 
Since the 2007 economic crisis, government investment in public works has declined sharply and so has implementation of the plan.

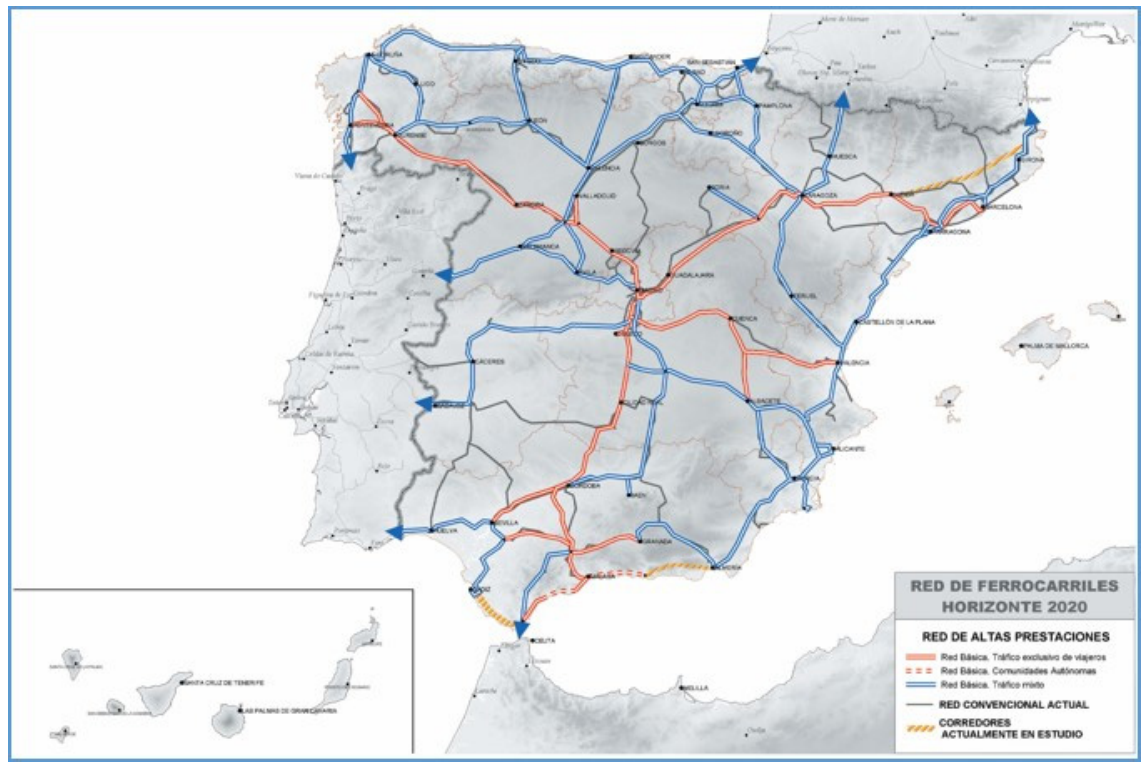

Figure 2: Actions foreseen in the Spanish railway network, PEIT 2020. (Source: Ministerio de Fomento, Spain.)

\section{Scientific paradigms for strategies for the localization of a high-speed train station and hypothesis testing}

In about 2000, the dominant scientific paradigm in Spain about the best location of train stations argued that location in a city centre is the optimal. However, this position was proposed for general long-distance rail services.

The new high-speed rail services call this paradigm into question. In 1996, COST 318 report [2] studied relations between high-speed rail and air transport and concluded, among others, that railway stations at airports allow for a better distribution of transport demand among airports. Also authors, such as Widmer and Hidber [3, 4] or others of the Institute for Transport Planning and Systems of Zurich [5] studied this question at that time.

The new paradigm proposes locating new high-speed train stations in airports in order to combine and integrate travel by airplane and by train. An intermodal station allows for travel with only one luggage check in. That is, passengers check the luggage at the start of the journey and reclaim it at their destination. In general, high-speed rail has replaced air travel of 300-500 km distance between the origin and destination and consequently increases the airport's hinterland and system transport efficiency.

However, when a high-speed station is located at an airport, the hinterland of the airport changes. The airport can service a more extensive regional area 


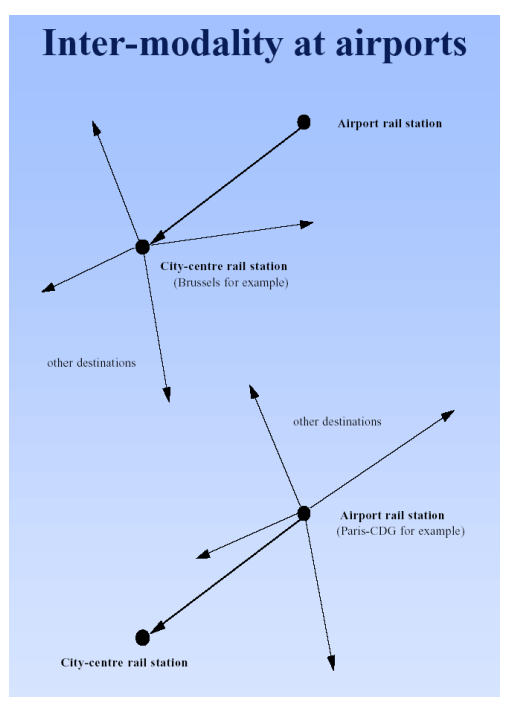

Figure 3: Two models to intermodal airports. (Source: Widmer and Hidber [3].)

connected by train. The hub airport has a hinterland of a medium sized airport and each medium sized airport has a hinterland by train of 300-500 km distance.

If the distance between a hub airport and a medium sized airport is about 300$500 \mathrm{~km}$ (1-2 hours' travel time at high-speed), then a medium sized airport can function as an extension of a hub airport. Passengers can travel to a medium sized airport and take a train to go to a main city. Depending on the operating times in the airports and the location of the train stations, this option can produce a better distribution of travel and a more efficient functioning of whole transport system. In any case, to integrate an air-train transport system, the railway station must be in an airport.

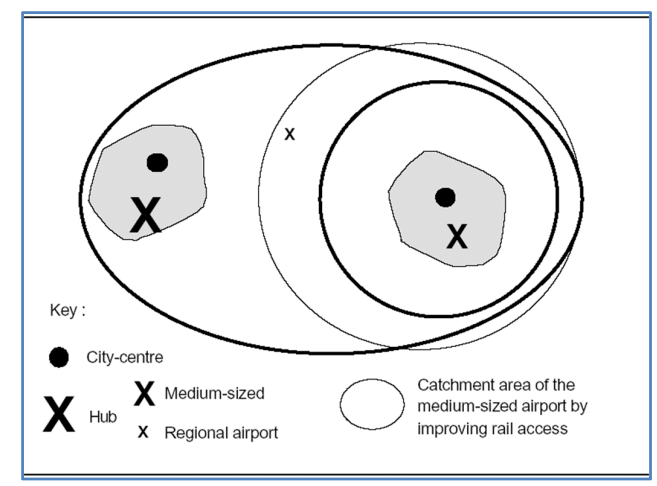

Figure 4: Hinterland changes by intermodal air-railway station. (Source: Widmer and Hidber [4].) 
This paper shows the evolution of the transport system air/high-speed train in Spain. This evolution allows for the testing of the hypothesis of an integrated system.

\section{Historical discussion in the Valencia case}

In the case of Valencia, in 1999, the central government, regional government and municipality signed an agreement to locate a high-speed station in the city centre. Thus, the study of alternatives of the public exposition in 2000 did not consider any other possibility. According to some municipalities, our research team, UDR F. Eiximenis, developed the possibility of a high-speed station in an airport [6]. This alternative has not been studied.

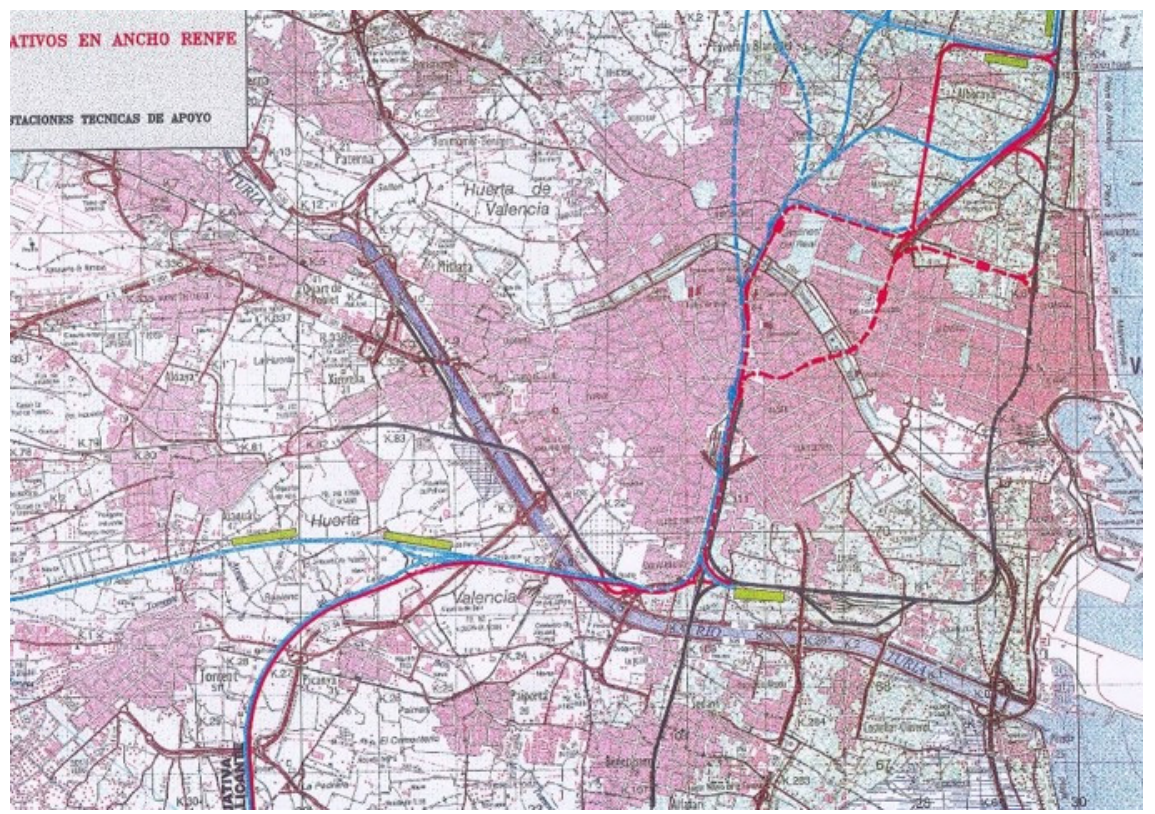

Figure 5: Public exhibition in 2000 of metropolitan rail network alternatives for Valencia. (Source: Ministerio de Fomento, Spain.)

Progressively more specialists are in favour of a high-speed station in an airport. In 2006, Ministerio de Fomento realized another public exposition with some changes but maintained the station in the city centre.

Barcelona City, with an approved project for its rail network metropolitan area, promoted a change to include a railway station at Prat Airport. Finally, after meetings with central and regional governments, the route of the high-speed line changed to include a new station in El Prat municipality, not at the same airport, and a connection by train with a new line to El Prat-Airport (about $6 \mathrm{~km}$ ). In 2010, central government first attempted to execute the works of a new line but it could 
not be performed because of economic problems (the works were awarded to a joint venture of construction companies but the process was stopped). Today, in 2015, the central government is trying again to execute the works which will probably commence next April.

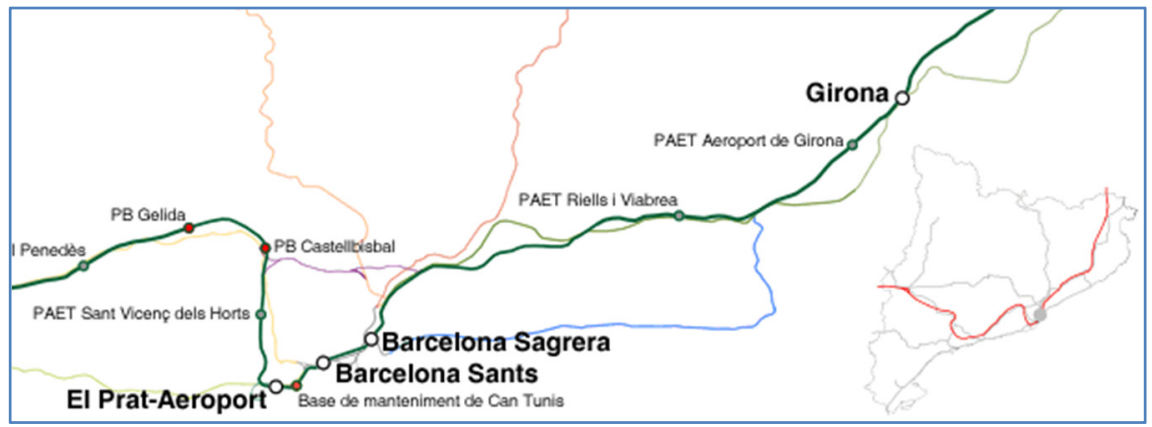

Figure 6: High-speed line and stations in Barcelona and Catalonia. (Source: ADIF (Administrador de Infraestructuras Ferroviarias, Spain.)

In 2005, a special urban plan of railway land and surroundings, Homologación y Plan de Reforma Interior del Parque Central, was exhibited to the public. The objective was to promote a green central park on the current surface of railway use when released. The plan was approved in March 2007.

In 2006, central government changed the solution and exhibited a new solution to the public. The first solution had planned to carry out a railway tunnel with two levels, one for the Iberian width and the other for the European width) below the historic city. It was really a complicated construction solution. The new solution planned the tunnel out of the historic city and with mixed widths (three rails which allowed for the two widths).

In this situation, when the southern entrance of the high-speed line already was in construction, our research team UDR F. Eiximenis, developed a new integration high-speed station with a city with two stations, one in the city centre and the other at the airport [7].

The design is complicated because it is necessary to combine terminal train travel with the Iberian width and the UIC width, and stations on the line, the trains stop and start to continue the trip, also with Iberian and UIC widths. In addition, the city and society want to put a Central Green Park on the land of the old railways park.

There is an official project planned for a new station next to the historical station (North Station, historical heritage built design by Demetrio Ribes architect in 1906) with a shopping center to generate income.

The intervention in this space also has urban consequences. An adequate design allows us to create a diagonal avenue that crosses the entire city.

Central government and Valencia municipality attempted an agreement to build a new high-speed railway station but without success. Finally, central government decided to build a temporary station. 


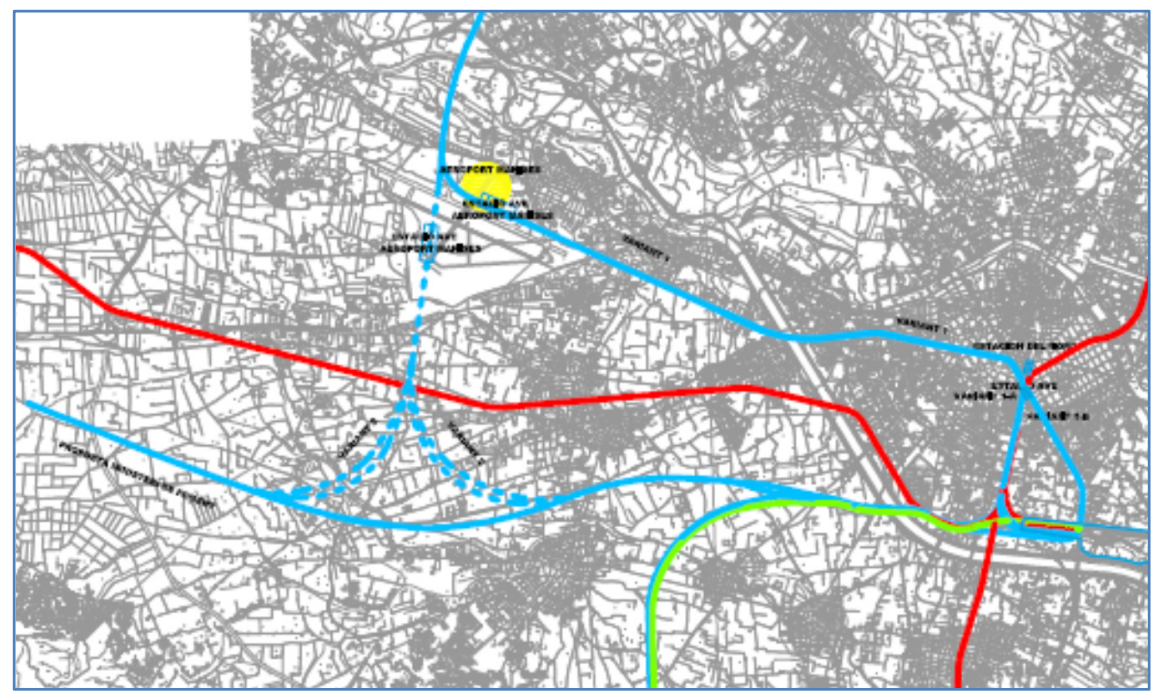

Figure 7: Study of solutions to integrate the high-speed station in Valencia City with two stations, centre and airport, 2006 (green line: in construction; blue line: high-speed planned; red line: conventional line). (Source: author.)

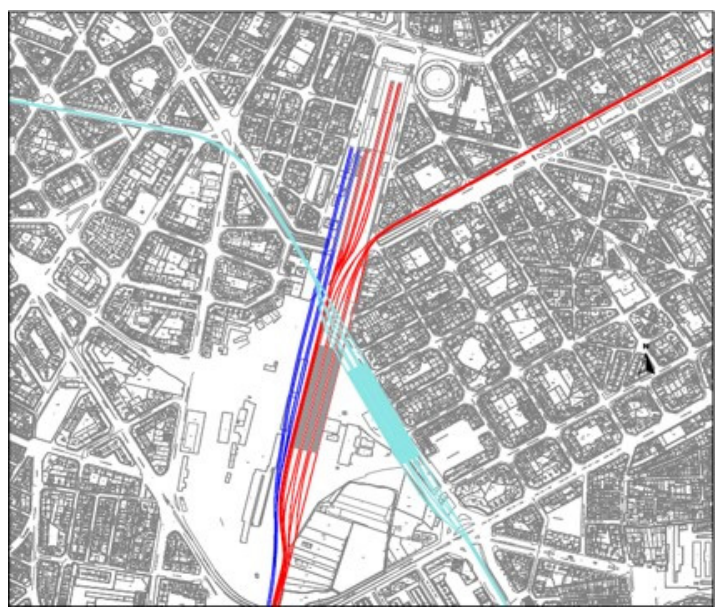

Figure 8: Study of solutions for a high-speed station in the city centre, 2006. Terminal station and line station with both widths, Iberian and UIC, and current location. (Source: author.)

\section{A new station in Valencia and new projects to Madrid}

A new station was built between April 2009 and December 2010. The station opened on 17 December 2010. At the moment, it is temporary but to date there is 


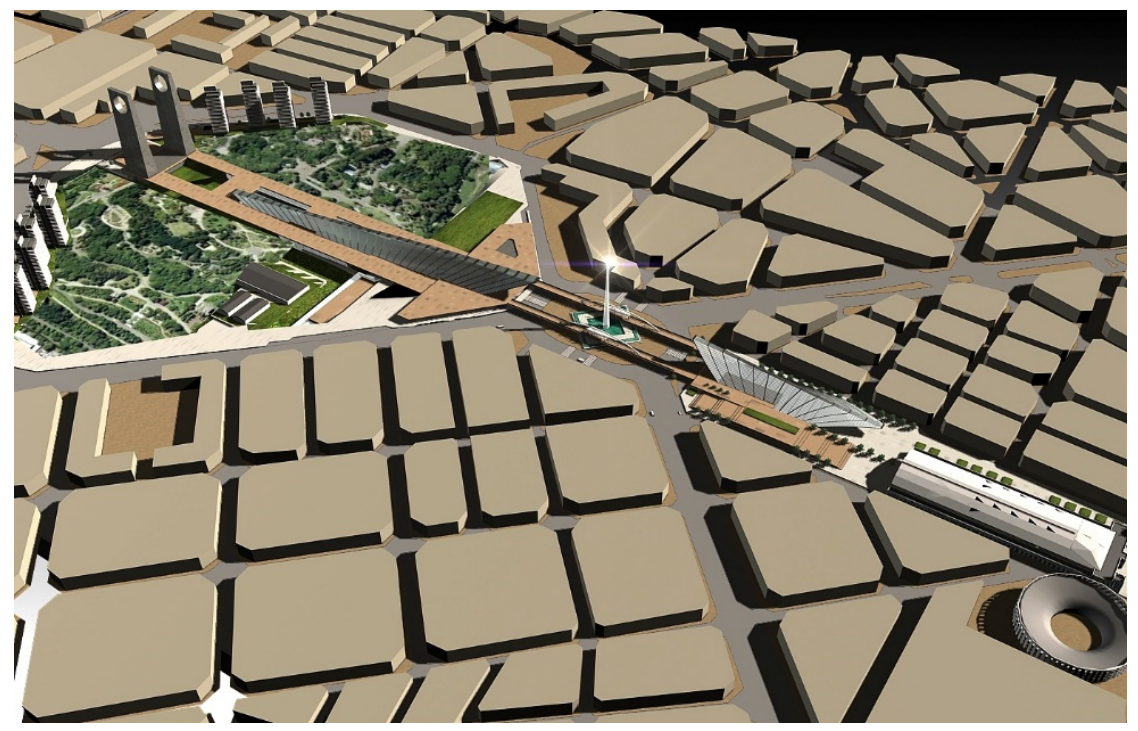

Figure 9: 3D simulation of train station and central park of UDR F. Eiximenis proposal design by Carlos Prieto architect, 2006. (Source: author.)

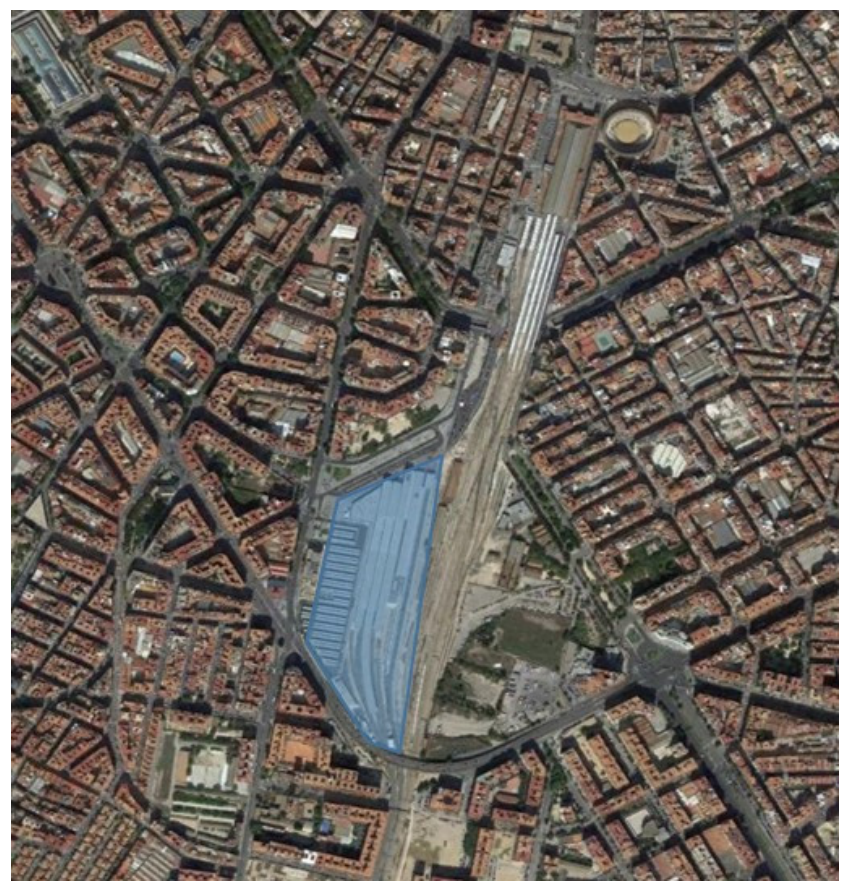

Figure 10: High-speed rail of Valencia, temporary station from 2010. (Source: Google and author.) 
no expectation of change. It is located west of the zone planned for central park, a distance of 800 meters from the main station. The nearest metro stop is 300 meters away, out of the station.

In 2009, the central government announced the project to connect a high-speed rail with Barajas Airport with the aim that any traveler can come directly from the airport by high-speed rail to Malaga, Seville, Valencia and Valladolid.

Regarding the project to connect by tunnel Barajas Airport with Chamartin Station. The project progresses slowly and has not been executed so far.

This decision is important because from the start, the high-speed railway station has a connection with Barajas airport by conventional train and by underground but without intermodal integration. The decision marks a change of approach to locating stations. An intermodal station airport-train allows a combined ticket flight-train with baggage at the start of the journey, to reclaim at the final destination.

In 2011, the institution Valencia Parque Central called an international ideas competition for designing this area with about 23 ha. Finalist projects were the proposals of Richard Rogers, Zaha Hadid, Adriaan Geuze, Kathryn Gustafson and Alejandro Zaera. The competition did not have practical consequences.

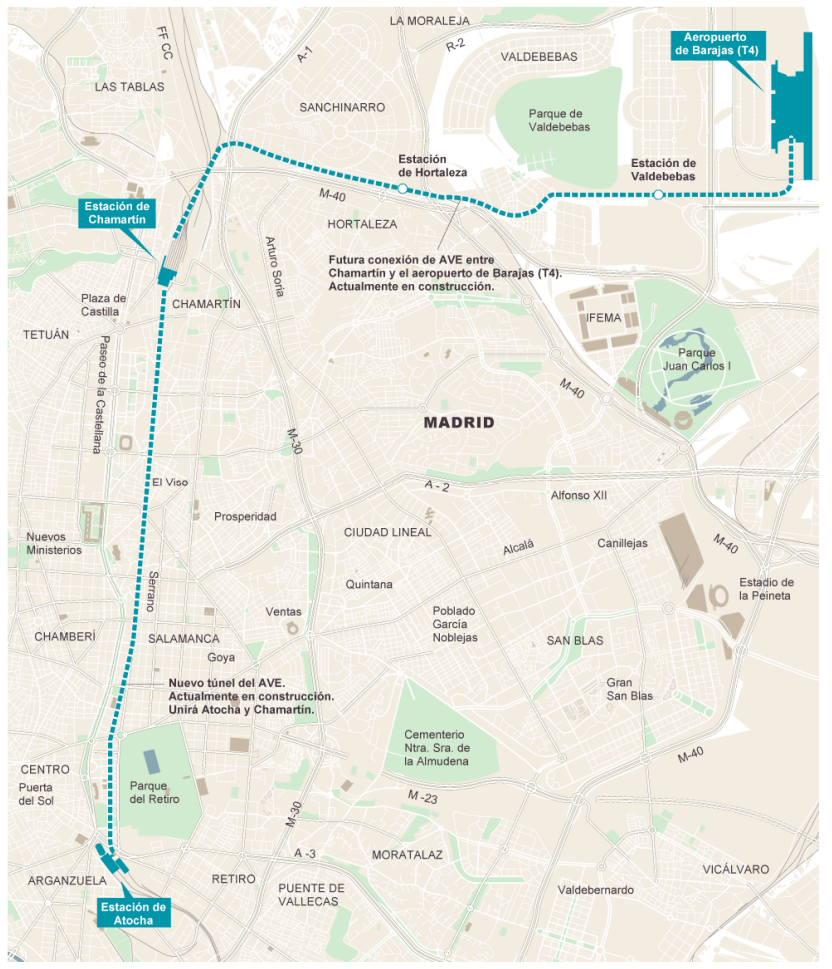

Figure 11: Project to connect Madrid high-speed rail station with Barajas airport. (Source: Ministerio de Fomento, Spain.) 


\section{Impact of high-speed train in modal distribution travel}

On the other hand, today we can analyze the impact of a new high-speed train service on intermodal passenger distribution, particularly between air and rail travel.

Conventional theory has established that high-speed rail is more competitive than air transport in origin-destination distances between 300 and $500 \mathrm{~km}$. The distance between Madrid and Barcelona is $505 \mathrm{~km}$ by air, $620 \mathrm{~km}$ by route and $621 \mathrm{~km}$ by high-speed rail. The distance between Madrid and Valencia is $302 \mathrm{~km}$ by air, $357 \mathrm{~km}$ by route and $408 \mathrm{~km}$ by high-speed rail.

In figure 12, you can see the number of passengers by airplane and by train travelling Madrid-Barcelona. You can see how, when the high-speed train started in 2007 by AVE, there was a decrease of air passengers and an increase of train passengers until a modal distribution of almost $50 \%$ for each mode of transport. In 2011, when ADIF changed the rate system, train passengers exceeded air passengers with a distribution about $60-40$.

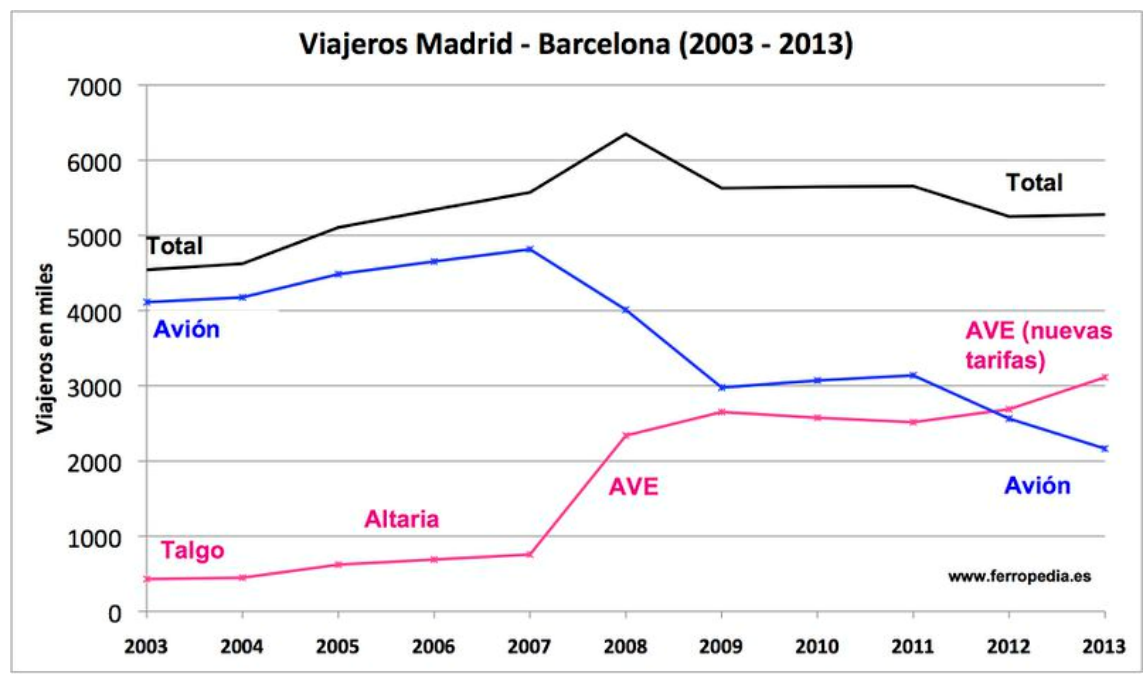

Figure 12: Intermodal distribution travels (thousands of passengers) air-train in the Madrid-Barcelona corridor. (Source: FERROPEDIA [9].)

Instead, in the case of Madrid-Valencia, shortly after starting a high-speed train service, modal distribution is $85-15$ in favor of the high-speed train.

These dates confirm the conventional theory about modal distribution between air and high-speed train travel. For a distance by route of $408 \mathrm{~km}$, the high-speed train captures almost all corridor travel. For a distance by route of $620 \mathrm{~km}$, the high-speed train is in a competitive limit with air mode although an appropriate pricing policy may favor the train. 


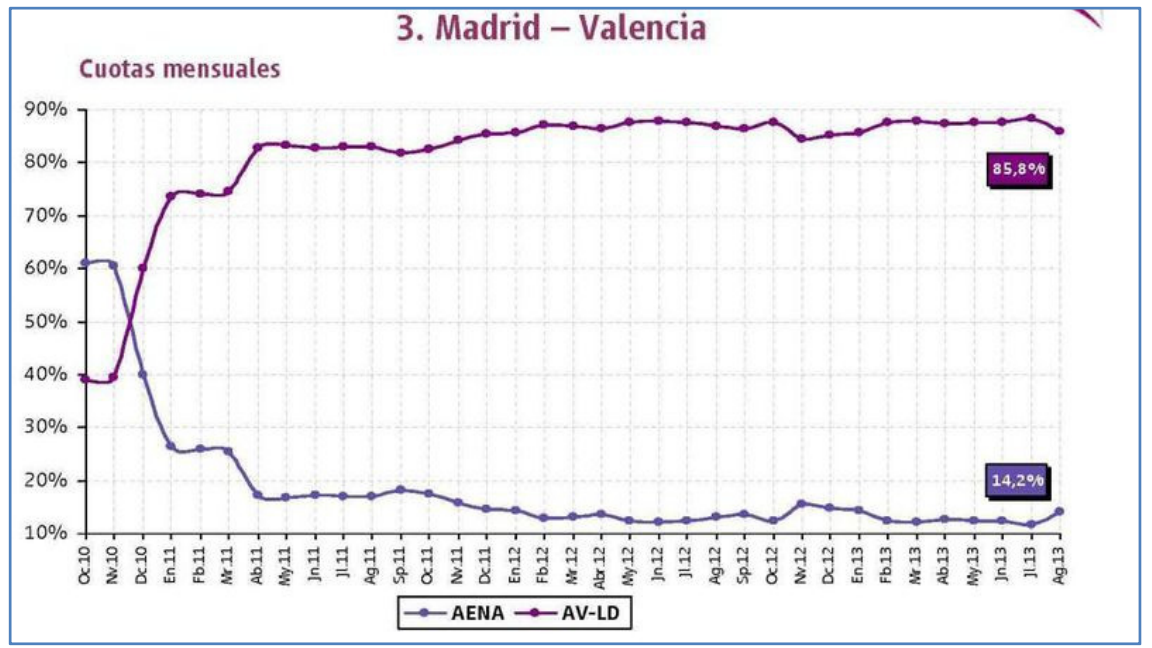

Figure 13: Intermodal distribution travels (\%) air-train in the Madrid-Valencia corridor. (Source: Ferropedia [10].)

\section{Conclusions}

According to experience in Spain, the trend is to connect a high-speed railway with an airport. Initially, the dominant paradigm was to locate a high-speed railway station in the centre of a city but, progressively, the trend has changed in favour of an airport connection and finally in favour of an intermodal station airport-high speed train.

On the Valencia-Madrid line with $408 \mathrm{~km}$ of distance by rail, modal distribution train-air is $85-15 \%$ in favour of a high-speed train. On the BarcelonaMadrid line with $621 \mathrm{~km}$ of distance by rail, modal distribution is $55-45 \%$ in favour of air transport but with an adequate pricing policy, modal distribution can change to $60-40 \%$ in favour of a high-speed train.

\section{References}

[1] Ministerio de Fomento. http://www.fomento.gob.es/MFOM/LANG CASTELLANO/_ESPECIALES/PEIT/PEIT2005Capitulo00_pdf.htm

[2] COST 318, Interaction between High Speed and Air passenger Transport; European Commission, Directorate General of Transport. www.cordis.lu/cost-transport/src/cost-318.htm

[3] Widmer, J.P. \& Hidber, C. Effects of Rail Station at Airports in Europe. Proc. of $79^{\text {th }}$ Annual Meeting of the Transportation Research Board. Transportation Research Board: Washington D.C., 2000.

[4] Widmer, J.P. \& Hidber, C. Do rail stations at airports allow a better distribution of passenger demand among airports? Proc. of $80^{\text {th }}$ Annual 
Meeting of the Transportation Research Board. Transportation Research Board: Washington D.C., 2001.

[5] Institute for Transport Planning and Systems, www.ivt.baug.ethz.ch

[6] Miralles i Garcia, J.L. L'estació intermodal de l'AVE a l'aeroport de Manises: una alternativa millor, Brosquil Edicions: Valencia, 2006.

[7] Miralles i Garcia, J.L. AVE, diseño y sostenibilidad: el caso valenciano. Proc. of V Congreso Nacional de la Ingeniería Civil. Colegio de Ingenieros de Caminos, Canales y Puertos: Madrid, 2007.

[8] Valencia Parque Central Alta Velocidad 2003, www.valenciaparquecentral.es

[9] Ferropedia. http://www.ferropedia.es/wiki/Tr\%C3\%A1ficos_AVE_y_ LD_corredor_Barcelona-Madrid

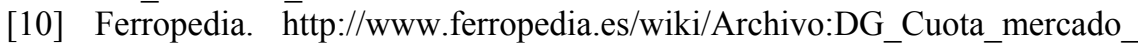
M-V_2012-2013_Grafico-renfe.jpg 